\title{
Benign Lymphoepithelial Lesion of the Salivary Gland
}

National Cancer Institute

\section{Source}

National Cancer Institute. Benign Lymphoepithelial Lesion of the Salivary Gland. NCI

Thesaurus. Code C3949.

\begin{abstract}
A benign lesion that involves the salivary glands, usually the parotid gland. It affects females more often than males and it may be a manifestation of autoimmune diseases such as Sjogren syndrome. There is an increased incidence of benign lymphoepithelial lesions in HIV-positive patients. It is characterized by the presence of a marked lymphocytic infiltrate and epi-myoepithelial islands in the affected salivary gland. Patients usually present with firm and painless swelling of the affected salivary gland. There is an increased risk for development of lymphoma.
\end{abstract}

